\title{
Assessing Community Contributions to Sustainable Food Systems: Dietitians Leverage Practice, Process and Paradigms
}

\author{
Liesel Carlsson, et al. [full author details at the end of the article]
}

Accepted: 28 September 2020 / Published online: 10 October 2020

(C) The Author(s) 2020

\begin{abstract}
Food systems are not sustainable, and efforts to address this are paralyzed by the complex networks of food system actors and factors that interact across sectoral and geographic scales. Actions at the community level can positively contribute toward globally sustainable food systems (SFS). Assessing such contributions has two central challenges: 1) a lack of methods that support alignment between communities and across scales, balanced against the need to involve the community in developing relevant indicators; and 2) the absence of adequate, fine grained data relevant to the community. Addressing these two challenges, this paper illustrates a proposed procedure that supports community engagement with, and assessment of, their contributions. Engaged by a community of Canadian dietitians, researchers used the Delphi Inquiry method, guided by the Framework for Strategic Sustainable Development, to address the first challenge, and causal loop diagrams informed by the Cultural Adaptation Template to address the second. Indicators were developed for dietitian-identified actions and outcomes for SFS. Modeling indicator interactions provide insight into how some actions are influenced by and reinforce the value placed on SFS within the professional cultural paradigm, as well as priority areas for action and measurement. Process-oriented assessment is useful in the context of partial and subjective understandings of a dynamic system, and supports continual adjustment in action. This article offers theoretical and practical insight for community engagement in addressing some of the systemic challenges in food systems. It accommodates communitybased knowledge, applies process-indicators, and emphasizes the importance of cultural paradigms as a driving force of community-level actions, and overall system change. Under current conditions, facilitating SFS literacy among dietitians can amplify adaptations for broader SFS development.
\end{abstract}

Keywords Sustainable food systems · Sustainable diets · Dietitians · Indicators · Assessment · Community - Framework for strategic sustainable development - Cultural adaptation template Delphi inquiry method

\section{Introduction}

Food systems are major contributors to unsustainable conditions in our ecological (Aleksandrowicz et al. 2016; Tara Garnett 2013; Gerber 2013; Willett et al. 2019) and social 
(IPES-Food 2015) systems. Swift, decisive, and collaborative action toward sustainable food systems are called for (EAT n.d.; Willett et al. 2019), but, such efforts are easily paralyzed by the complexity of the issue, involving networks of food system actors and factors that interact across sectoral and geographic scales. At global and national levels, progress has been made toward developing comprehensive sustainable food systems (SFS) assessment tools, which accommodate this multidimensional systems perspective, and that can track progress on SFS (Allen and Prosperi 2016; Feenstra et al. 2005; Prosperi et al. 2014; The Economist Intelligence Unit and Barilla Centre for Food and Nutrition 2016; Zurek et al. 2016). However, ways by which people engage with food systems, through expression of food culture, eating habits, and institutional actions, are often rooted at the level of community. ${ }^{1}$ Unfortunately, progress toward SFS assessment tools for guiding action at a community level has been much slower.

Being able to assess how community level actions and policies contribute to SFS development is an important mechanism for promotion of community level engagement in SFS development (Alrøe et al. 2016). Examples of assessment tools (Scialabba et al. 2014) that have been used to inform policy related SFS measurement in city regions (Colombo et al. 2019; Landert et al. 2017), and sustainability performance of food value chains (Gamboa et al. 2016; Peano et al. 2015), provide insight that informs potential indicators for use at the community level. However, community level assessment faces two central challenges.

The first is a lack of tools or methods that support synergistic progress among communities, and across scales with the broader global efforts toward SFS. Synergistic progress is complicated by a well-recognised need for community involvement in the process of indicator development. Community involvement greatly enhances the likelihood that assessment methods and tools will foster engagement, reflection and learning among participants, and thus encourages continual adjustment within the dynamic system (Alrøe et al. 2016; Fraser et al. 2006; Lyytimäki et al. 2018; Sterling et al. 2017); however, it decreases the likelihood of synergy between and across systems. The second challenge is the relative lack of consistent, high quality, and reliable data at the community level — a phenomenon not unique to food systems assessment (Lyytimäki et al. 2018). The data needs are high, given the multidimensional and multiscalar nature of food systems and sustainability.

To address the first challenge, previous work (Carlsson et al. 2017a) by this author team proposed a process for engaging communities in defining local indicators as part of a framework that acknowledges the systemic, dynamic nature of food systems sustainability challenges (Soubry et al. 2020). With respect to the second challenge, it remains unresolved, as our initial inquiry found that the practical process of collecting data created enormous and shifting demands for data not available at the community level, required expensive and time consuming methods, and was not feasible for communities continue over time.

Since assessment work is important to continually re-evaluate actions in a dynamic system, the purpose of this paper is to build on our work to solve this second challenge by adding further methodological support for assessment in the absence of adequate data. In this paper we describe a concrete procedure that addresses these two challenges together, and illustrate using a community case study with Canadian registered dietitians (RDs).

The community of RDs was deliberately chosen given their diverse roles throughout food systems. A promising body of evidence points to the potential for behavior change with respect to dietary choices (Aleksandrowicz et al. 2016; Chai et al. 2019; IPCC 2018;

\footnotetext{
${ }^{1}$ A community can be defined by its geographic scope (e.g., a city), as well as by sociological orientation such as cultural identity, common purpose or experience, etc.
} 
Ranganathan et al. 2011; Willett et al. 2019) and food policies (Garnett et al. 2013; Garnett 2014; Lang and Mason 2017) to contribute to solutions for a sustainable food future (Garnett 2013, 2014; Lang and Mason 2017). Some behavioral changes, such as a move toward plantbased diets, are gaining attention for their co-benefits to human health and ecosystem sustainability (Berry et al. 2014; Nelson et al. 2016). Further, the choices people make around what foods to eat are influenced strongly by social and cultural factors (Sobal and Bisogni 2009), and cultural and social norms shift over time in relation to local and global contexts. As part of the evolving discourse around sustainability and food, RDs are exploring ways to use their expertise to facilitate diet-related behaviour change, and affect social and cultural norms toward supporting sustainable dietary choices and food systems.

\section{Methods}

The methods and theoretical frameworks that guide the research in this context are summarized here, and in Table 1, as they relate to their role in addressing the two central research challenges. Following, each method is described and justified in greater detail. The specific sequence of steps, or procedure used to apply the methods and tools, is detailed in Appendix 1.

As a first step to addressing the challenges identified in the introduction, researchers used the Delphi Inquiry method (Kezar and Maxey 2016), guided by theoretical and methodological supports from the Framework for Strategic Sustainable Development (FSSD) (Broman and Robèrt 2017). The paring of the Delphi Inquiry method with the FSSD, allowed the researchers to engage in an evolving, detailed, iterative discussion with participants about SFS, while maintaining grounding with the larger abstract concept of sustainability.

Causal loop diagrams (CLDs) informed by the theoretical and methodological supports from the Cultural Adaptation Template (CAT) (Dyball and Newell 2015) were chosen as a

Table 1 Summary of methods used to address the assessment challenges

\begin{tabular}{|c|c|c|c|}
\hline $\begin{array}{l}\text { Assessment challenge addressed } \\
\text { in this article }\end{array}$ & $\begin{array}{l}\text { Method/ } \\
\text { Tool used }\end{array}$ & $\begin{array}{l}\text { Theoretical } \\
\text { framework }\end{array}$ & Rationale \\
\hline $\begin{array}{l}\text { Developing methods and tools that } \\
\text { support synergistic SFS progress } \\
\text { between communities and across } \\
\text { scales, while involving } \\
\text { community in developing } \\
\text { indicators relevant to the } \\
\text { community. }\end{array}$ & $\begin{array}{l}\text { Delphi } \\
\text { Inquiry } \\
\text { Method }\end{array}$ & $\begin{array}{l}\text { Framework for } \\
\text { Strategic } \\
\text { Sustainable } \\
\text { Development }\end{array}$ & $\begin{array}{l}\text { Increased community involvement } \\
\text { in indicator development. } \\
\text { Providing objective parametres of } \\
\text { sustainability to guide alignment } \\
\text { between communities and across } \\
\text { scales. } \\
\text { Articulating in what way } \\
\text { communities contribute to } \\
\text { sustainability. }\end{array}$ \\
\hline $\begin{array}{l}\text { Accommodating the absence of } \\
\text { (especially) community level data. }\end{array}$ & $\begin{array}{c}\text { Causal Loop } \\
\text { Diagrams }\end{array}$ & $\begin{array}{l}\text { Framework for } \\
\text { Strategic } \\
\text { Sustainable } \\
\text { Development } \\
\text { Cultural } \\
\text { Adaptation } \\
\text { Template }\end{array}$ & $\begin{array}{l}\text { Avoiding unknown (lack of data) } \\
\text { problems by upstream definition } \\
\text { of sustainability. } \\
\text { Hypothesize dynamic indicator } \\
\text { relationships between and across } \\
\text { scales. } \\
\text { Make inferences without access to } \\
\text { all desired data. } \\
\text { Make inferences about the influence } \\
\text { of sociocultural norms. }\end{array}$ \\
\hline
\end{tabular}


promising additional method to make inferences about the relationships between food system factors without access to all desired data (Leischow and Milstein 2006), to hypothesise the dynamic relationships between variables (Davila et al. 2018) (expressed as indicators), and to highlight the important role of sociocultural norms (paradigms) (Dyball and Newell 2015) in community level SFS development.

\section{Delphi Inquiry Method}

Researchers were invited to work with the community of Canadian RDs to gain an understanding of how they conceptualize SFS, what inhibits and facilitates movement toward SFS, and in what ways we can track progress toward this preferred state. This invitation was in response to an organizational priority to support the members of the profession to be ready to support this interprofessional/intersectoral work (Sharp 2016a). One member of the research team is a Canadian RD (LC), and therefore a member of this community. Their role was as a research team member as well as a member of a professional leadership team communicating with members and the profession. This research team member provided a critical link between theory and scholarship, and practical professional realities.

Food systems are complex, dynamic, socioecological systems of food production, distribution, consumption and management of waste flows. The meaning and purpose ascribed to our food system are emergent, shifting over time and space, and influenced, in part, by one's role within the food system (e.g. eater, farmer, dietitian, etc.). For a community of practitioners to comprehend the significant complexities associated with tracking progress toward sustainable food systems, but to never-the-less imagine potentially effective actions and indicators for tracking progress, first requires that community to also comprehend the systemic challenges and scalar nature of the food system itself.

The Delphi Inquiry method (Hasson and Keeney 2011) was used to engage with the community to co-create a plan for contributing to sustainable food systems, and specific to this article's focus, in developing indicators relevant to the community. This method has been used to develop metrics for food systems sustainability (Allen et al. 2019), well suited to facilitate participatory approaches (Kezar and Maxey 2016). The method engages researchers and participants in three rounds of iterative call-and-response type discussion that allows researchers to listen carefully to the responses of participants, then share back with participants an anonymized composite summary of all participants' responses. In between rounds, participants have time to reflect on the composite responses in relation to their own, and then another opportunity to respond to the same questions in light of the other participants responses as reflected in the researchers' composite. This method is appropriate for grappling with abstract concepts that require a degree of consensus to make them actionable (Rikkonen et al. 2006; Thomas et al. 2019), and for bringing to the fore the community's system of values that influence their relationship to the system of interest - an important component of soft systems thinking (Checkland 1981; Flood 2010). Hosted online and with confidentiality maintained, the method supports free expression and is useful for working with geographically dispersed communities.

Participating Canadian RDs were asked to reflect on questions through three iterative, online rounds of discussion. The questions asked Canadian RDs to describe: (1) their vision of a sustainable food system in Canada, (2) current barriers to the vision, (3) what actions would be most effective in achieving the vision, and (4) what indicators are necessary to assess progress toward the vision. Instead of focusing on specific, hard goals of sustainability or SFS, 
these questions encouraged participants to imagine success, and the myriad ways by which it could be achieved. This flexibility is critical as there is no one-size-fits-all solution for sustainable food systems, and honours cultural and geographic differences among participants. It also allowed researchers to understand qualities of the system that are meaningful to the participants.

After each round of questions, using qualitative, open coding and theming, the research team analysed the results and developed a composite summary of responses that was sent to participants to consider in advance of answering the same questions again in subsequent rounds. The composite summaries reflected participants' perspectives verbatim where possible. Common themes were identified, and areas of dissent were articulated. In responding to the composite summaries, participants were invited to amplify ideas, express any disagreements, or ask for clarifications regarding information in the summary. This process was iterative, with cycles of data collection and analysis, and fostered learning between and among participants and researchers. A fourth and concluding round of the Delphi Inquiry process, a face-to-face workshop, allowed participants to finalise discussions from the online results. The iterative nature of the Delphi is a form of member checking, and contributed to trustworthiness (Neuman 2011; Yin 1994) in the data, including development of indicators relevant to the community.

\section{Framework for Strategic Sustainable Development}

The Framework for Strategic Sustainable Development (FSSD) (Broman and Robèrt 2017) was used as a theoretical framework for the Delphi. The FSSD has been designed to support a socioecological systems understanding of the global sustainability challenge, and offers methodological supports to help actors (organizations, communities) articulate the way in which they can strategically act to support broader sustainability. Three methodological supports of the FSSD were used: Backcasting, the Sustainability Principles (SPs) and the Five Level Model (5LM).

\section{Backcasting from Sustainability Principles}

Delphi Inquiry process described above was informed by a procedure for Backcasting planning and redesign toward a principles-framed vision, shortened to 'Backcasting from Sustainability Principles (SPs)' (see next section for description of SPs). Consistent with a soft systems approach (Flood 2010), backcasting has been used with organizations and communities to understand socioecological systems conditions and co-create pathways toward sustainable futures (Hebinck 2018; Kok et al. 2011). In this case, the process was used for cocreation (between and within the community and researchers) of strategic transitions toward sustainable food systems through the following steps:

A. Create a vision of success framed by the above principled definition of sustainability.

B. Gather baseline information regarding the current reality, assess the system under question in relation to the vision of success (gap analysis), and clarify current strengths and challenges.

C. Generate creative solutions for making progress from the current reality to the vision of success.

D. Prioritise among the generated actions. 
These steps informed the questions used in the Delphi Inquiry method described in 2.1.

\section{The Sustainability Principles}

We cannot know now what our possible sustainable future will be (or even if it will come to be) as it will emerge overtime through multiple complex interactions of stakeholders across the globe. We do, however, know what categories of behaviors inhibit progress toward a sustainable future.

The eight Sustainability Principles (SPs) (Table 2) within the FSSD identify principles to guide our behavioral relationship with the earth and each other for a sustainable future. According to an FSSD approach, sustainable food systems must not contribute to violations of the SPs. Their iterative development and justification is described elsewhere (Broman and Robèrt 2017). The SPs have been used as an operational definition of sustainability to provide objective parametres that facilitate systems thinking about the challenges and opportunities for moving toward sustainability (Morgan et al. 2017).

As can be seen in Table 2, the SPs demonstrate a clear, and broad scope of sustainability, inclusive of both ecological and social issues with more fine-grained boundary constraints than the more broadly used reference to social, ecological, economic dimensions. Within the boundary constraints set by the SPs there are myriad possibilities for sustainable futures (Broman and Robèrt 2017). Thus, the SPs provide objective parametres for sustainability that, if applied at the local level (organization or community), between communities and across scales can help guide concerted action (Holmstedt et al. 2017).

The SPs were used in this research as a priori coding themes for the Delphi Inquiry data to maintain rigor in the coding process that both reflected the diversity of ideas and allowed a degree of parsimony.

With respect to development of indicators in this research, the SPs were used again in articulating the ways in which community level actions contribute toward or away from sustainability, or more specifically, the community's vision of success within the boundaries of the SPs.

\section{The Five Level Model}

To facilitate understanding of a system under study, and action toward a more sustainable state in that system, the FLM stratifies five levels of information.

Table 2 A principled definition of sustainability, articulated as eight sustainability principles (SPs)

SP1

SP2

SP3

In a sustainable society, nature is not subject to systematically increasing ... concentrations of substances extracted from the Earth's crust (e.g., fossil carbon); concentrations of substances produced by society (e.g., pesticides); and degradation by physical means (e.g., over harvesting fish).

... and people are not subject to structural obstacles to ... 
1. The system level includes essential aspects for a sustainable socioecological system of focus, including both sub-elements of a system as well as the system's inter-relations to other systems, and descriptions of interrelations among these.

2. The success level includes a vision of success framed by a principled definition of sustainability (8SPs).

3. The strategic guidelines level provides guidelines for prioritizing actions toward the vision of success.

4. The actions level includes concrete actions organised in a strategic plan.

5. The tools level includes concepts, methods, tools and other forms of support for decision making and working with the above levels.

The 5LM was used in analyzing the Delphi Inquiry data to separate and structure different data types, e.g., to isolate responses about a problem in the system such as food insecurity (system level) from what is envisioned - food security (success level), from possible ways of achieving it (actions or tools levels). In this way, the FLM supports action-oriented research.

\section{Causal Loop Diagrams}

Causal loop diagrams (CLD) are tools used in systems sciences to help illustrate variables and relationships within a system. In public health they have been used, for example, to set realistic benchmarks for illustrating hypothesised public health indicator relationships where it would otherwise be challenging to measure variables in isolation (Luke and Stamatakis 2012). As such, CLD can be helpful in the absence of adequate, or directly comparable data, because the state of one variable can be inferred from relationship to, and the state of related indicators.

After completion of the Delphi Inquiry process and using the Cultural Adaptation Template (CAT, described below) as a theoretical framework, researchers developed CLD to help delimit and visualise the relationships between the proposed indicators in the system of interest. In this paper, the system of interest was the Canadian RD community's engagement SFS knowledge development. This was an action area identified by the community.

The indicator list that resulted from question four in the Delphi Rounds served as a member informed list of potential indicators that could help track progress toward, and achievement of, the desired vision (i.e. Canadian community of RDs is knowledgeable about and incorporating SFS into practice). Actions that were considered to have deep leverage (Abson et al. 2017; Meadows 1999) were used to inform community level indicator development to assess how, if at all, community actions (i.e., those of the dietetics community) affect broader food systems sustainability outcomes (articulated as themes, see Table 4).

Literature and publicly available, free, databanks (e.g., Food and Agriculture Organization) were reviewed for possible data sources or alternative, practical facsimiles which captured participant ideas. The research team then screened the potential indicators against the following criteria: necessary, sufficient, practical and high quality.

\section{Cultural Adaptation Template}

The CAT has been developed to theorise the nature of relationships between factors that drive the capacity of a culture to adapt in a way that is sustainable (i.e., their adaptive capacity to survive into the future) (Dyball and Newell 2015). These factors are: cultural paradigms, community, human health and wellbeing, and ecosystems. They are illustrated using causal 
loop diagrams as shown in Fig. 1 (Dyball and Newell 2015). The CAT has been used to study sustainable management of food subsystems (El Hassan 2019), and it has been applied in work with communities to understand and capture structural similarities in food and nutrition discourse, frame worldviews, and identify variables which can be used to analyze the links between the four factors of the CAT (Davila et al. 2018). As such the CAT is helpful to understand the role of communities in contributing to the sustainability of complex socioecological systems (such as food systems), and to identify community-informed variables for assessment.

The CAT theorises how the state of cultural paradigms (mental models, belief systems, underlying assumptions) in the system of interest influence, and in turn are influenced by, the state of the community (CLD links 1 and 2 respectively), ecological factors (link 6), and human health factors (link 4). These influences can create either reinforcing or balancing feedback loops. This model can indicate relationships across scales and help illustrate how the state of a community (and a specific factor within that community) has influence over health (link 3) and ecological (link 5) outcomes. The CAT separates the state of cultural paradigms as a unique subsystem because of the influential role of cultural paradigms in influencing social and cultural norms (such as dietary choices) at the community level, and therefore the ability of a culture to adapt (survive) in changing environmental conditions.

\section{Results}

Results of the Delphi process uncovered existing structures in the socioecological system that are barriers to the vision, in what way barriers contribute to unsustainable conditions, and actionns for addressing each barrier (for further detail on this analysis, see (Carlsson et al.

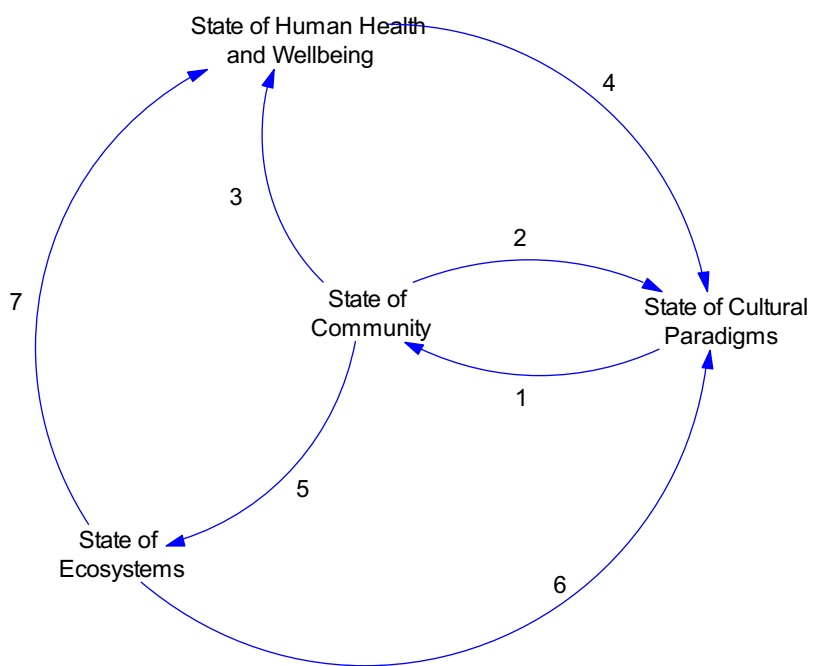

Fig. 1 Cultural adaptation template. Footnote to Fig. 1: Reproduced from Dyball and Newell (2015) with permission. The direction of the relationship between variables is shown by an arrow, but not the polarity $( \pm)$ of the relationship. The numbered arrows help orient the reader to a relationship in question. Figure 1 prepared using Vensim ${ }^{\circledR}$ 7.3.5. 2019 
2019a)). The relationships among vision theme, barriers, SPs, and actions for Canadian Dietitian sustainable food system knowledge development is shown in Table 3.

The methods and results of Delphi questions one through three have been previously published (Carlsson et al. 2019a), in a journal targeted to this community audience, and a final report to the community, which both examined and related the vision themes against barriers and high-leverage action. The latter was formatted for use as a roadmap (Carlsson et al. 2017b) and is being used to inform other strategic work (Dietitians of CanadaSustainable Food System n.d.; Sharp 2016b).

The methods and results of questions one through three will be included in this paper in only enough detail to provide context for the assessment procedure. This paper builds on a subset of the results mentioned above, as well as unpublished data from question four, in developing the assessment process.

\section{The Community Defines their Vision}

A vision was established to guide actions and assessment processes which showed that that RDs have a multidimensional understanding of the complex and interrelated ecological and social concepts of SFS (Carlsson et al. 2017a). The vision represents what is important to the community at the particular time they were surveyed. Different themes may arise in other communities and/or at another time where different contexts and cultural paradigms dominate. The vision is bounded by the condition that the state does not violate any SPs.

Among many other dimensions (Carlsson et al. 2017a, 2019a), RDs envisioned that “... Canadians have the capacity to produce, access, and prepare food, reflect and act on the socioecological implications of their food choices. ... They support a healthy relationship with

Table 3 Barriers facilitating sustainable food systems knowledge development, sustainability violations, and upstream actions

\begin{tabular}{|c|c|c|}
\hline Barriers & $\begin{array}{l}\text { SPs violation } \\
\text { (Broman and } \\
\text { Robèrt 2017) }\end{array}$ & Actions \\
\hline $\begin{array}{l}\text { Competing food-health sustainability mes- } \\
\text { sages that lack scientific evidence }\end{array}$ & SP5 & $\begin{array}{l}\text { Develop common language and shared } \\
\text { understanding of SFS within the profession } \\
\text { Identify and dispel common myths about SFS } \\
\text { Develop a "case" for sustainability using both } \\
\text { dietetic and publicly accessible language }\end{array}$ \\
\hline $\begin{array}{l}\text { Inadequate opportunities for developing } \\
\text { understanding of the interactions } \\
\text { between food, people and the } \\
\text { environment }\end{array}$ & SP6 & $\begin{array}{l}\text { Educate for SFS literacy in public schools \& } \\
\text { community } \\
\text { Advocate for integration of SFS in provincial } \\
\text { education curricula } \\
\text { Include SFS literacy in dietetic education } \\
\text { Advocate for integration of SFS in national } \\
\text { dietetics curricula }\end{array}$ \\
\hline $\begin{array}{l}\text { Cultural expectations of, and stable access } \\
\text { to, a variety of imported foods } \\
\text { year-round }\end{array}$ & SP1 & $\begin{array}{l}\text { Educate about satisfying food and nutritional } \\
\text { needs in a way that is less reliant on energy } \\
\text { and transport intensive practices }\end{array}$ \\
\hline Cultural de-prioritization of food & SP4 & $\begin{array}{l}\text { Advocate and educate for prioritizing cultural } \\
\text { food (e.g., creating time for meals in homes } \\
\text { and institutional settings) }\end{array}$ \\
\hline
\end{tabular}

Reproduced with permission (Carlsson et al. 2019a). The actions described by RDs use the language "SFS literacy." In this paper SFS literacy is part of and contributes to food literacy 
food, such that Canadians value food, its origin and quality, and express identity and culture through foods..." (Carlsson et al. 2019a, p. 3 p.3). In this article, the vision theme "food literacy" represents the concepts in this portion of the RD vision, and is the focus of the following sections. Narrowing to one theme simplifies the example to a conceptually manageable size for this article. Using food literacy as an example is strategic as there are currently no commonly accepted indicators.

According to Cullen et al., food literacy is inseparable from the concept of SFS; food literacy "... is the ability of an individual to understand food in a way that they develop a positive relationship with it, including food skills and practices across the lifespan in order to navigate, engage, and participate within a complex food system. It's the ability to make decisions to support the achievement of personal health and a sustainable food system considering environmental, social, economic, cultural, and political components"(Cullen et al. 2015, p. 143 p. 143). As such, food literacy requires foundational knowledge (or literacy) in SFS.

\section{The Community Defines Barriers to the Vision and High Leverage Actions}

The Canadian RD community identified 'facilitating knowledge development' as one of three action areas for dietetic contributions to global SFS (Carlsson et al. 2019a). Facilitating knowledge development for SFS literacy contributes to food literacy, as per the above definition.

Within this action area, Canadian RDs distilled central barriers to SFS literacy and specific actions that would help address these barriers, intended to lead to a higher level of SFS literacy among RDs, and also the public, thus supporting movement toward the vision.

Table 3 summarises the barriers, identifies the primary way in which they violate SPs, and highlights upstream actions RDs perceived to be their greatest leverage points to overcoming the barriers. Presented this way, barriers and actions are components of driving forces which influence and indicate whether food literacy is moving toward or away from being supportive of sustainability.

\section{The Community Identifies Relevant Outcome and Process Indicators}

The proposed indicators measure one of two things: outcomes and process. Outcome indicators were based on the themes captured in the vision - how do we know we have achieved one of our "end goals," like food literacy, while process indicators capture action-how are we contributing movement toward food literacy? Table 4 is organised by outcome and process indicators relevant to the issue of food literacy. Each outcome, or process, is described, a method of measurement is proposed, data sources are identified, and a summary of the strengths and limitations of that indicator are provided.

\section{Assessing How Actions at the Community Level Contribute to Global SFS Development}

Without an existing measure of food literacy, measuring actions (process indicators, see Table 4) provides a way for this community to assess their contributions to food literacy. These process indicators are informed by practice-based expertise. As actions that address SP violations, in theory, they should help drive action toward a sustainable state. 


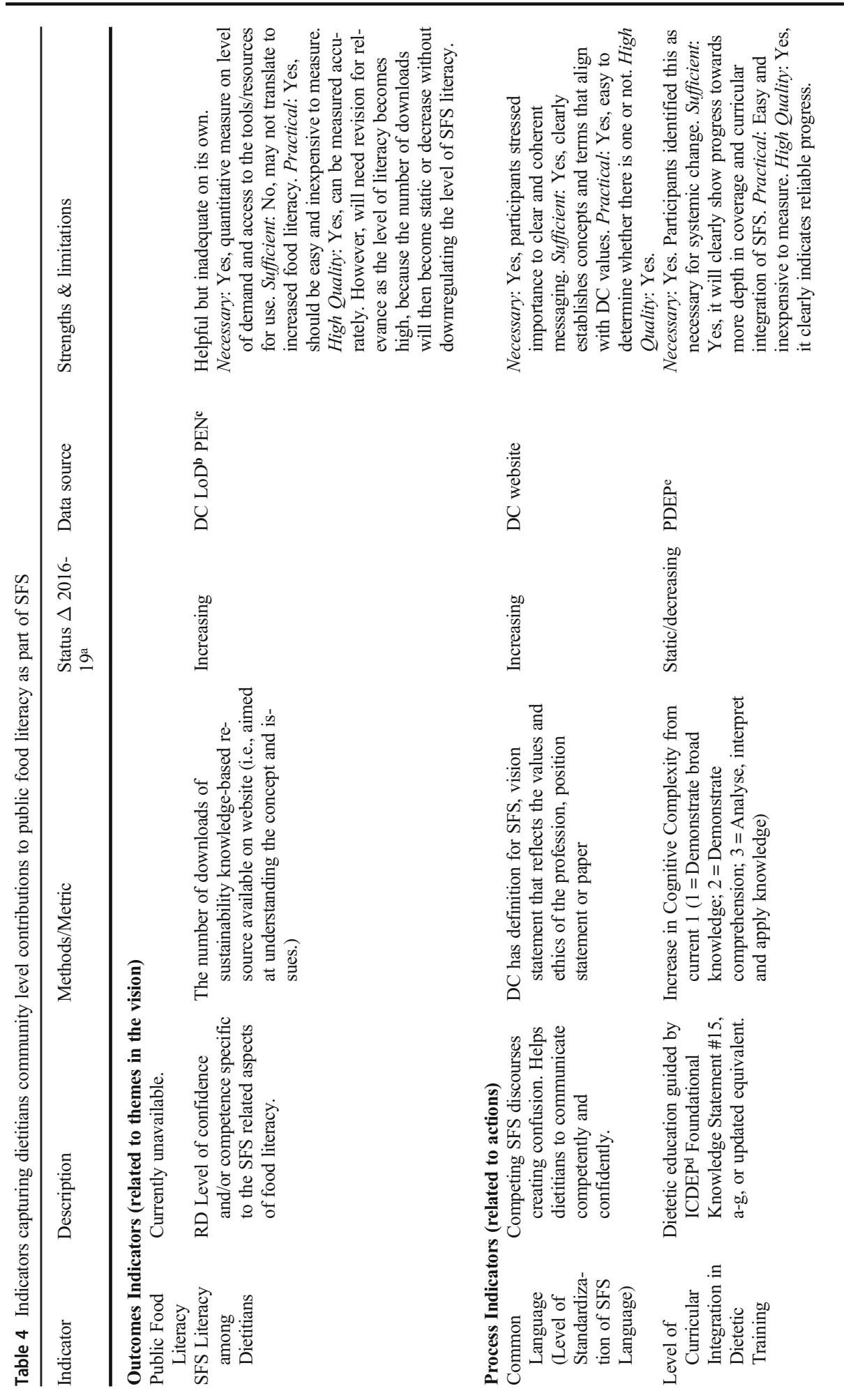




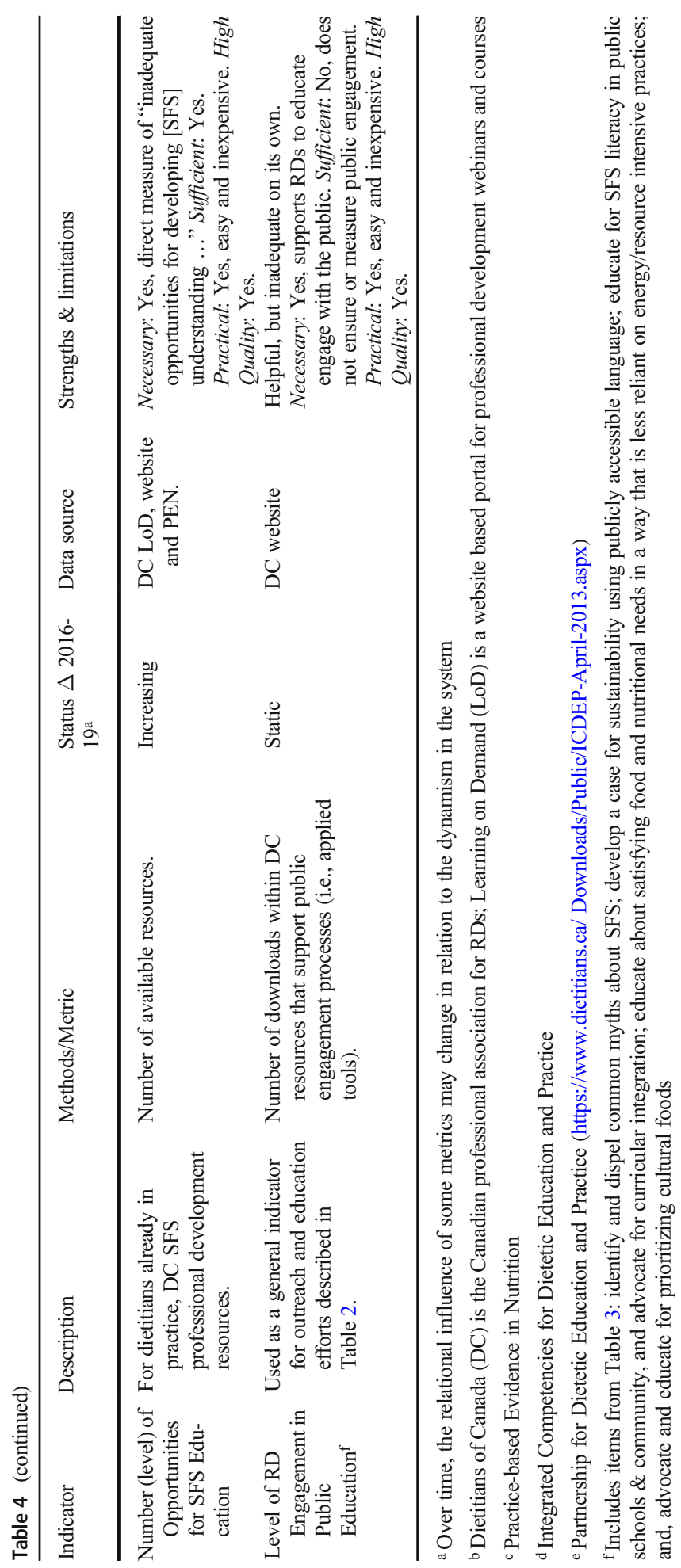


Using the CAT as a model, Fig. 2 shows the subsystem of interest, food literacy, as part of SFS. Figure 2 illustrates the nature of the relationships between the state of cultural paradigms within the profession (the level of focus on SFS in Canadian dietetic practice), the state of the community (the level of RD SFS literacy), the state of ecosystems (e.g., climate) and the state of human health and wellbeing (e.g., public food literacy). The state of the community is not simply about the level of knowledge that RDs hold, but rather the formal and informal structures that influence collective behavior among individual practicing RDs (formal positions that guide policy, education and practice, as well as informal normative standards that influence practice). This differs from the state of the cultural paradigms within the profession, which represent the collective knowledge, beliefs and values that govern the communities' judgments. An example of an SFS focused paradigm would be one which reflects the values position that was described in this case study, one in which "health, social, economic and ecological outcomes carry equal weight ..." (Carlsson et al. 2019a, p. 6 p.6) in guiding professional practice.

The relationship between variables is indicated with either a positive $(+)$ relationship, meaning when one increases, the other does as well, or a negative (-) relationship, where when one increases, the other decreases. In some relationships, there is a time delay (II). The theme food literacy is a variable which RDs want to increase (+), and exists at all scales. Climate stability, which is global in scale (Fig. 2) is included to illustrate the multiscalar capabilities of the proposed procedure, but not part of the example indicators outlined in this paper.

Currently, there are two process indicators (Level of Standardization of SFS Language, and Level of Opportunities for SFS Professional Development) that are increasing, which is directly related to the increasing outcome indicator measuring food literacy among RDs (see

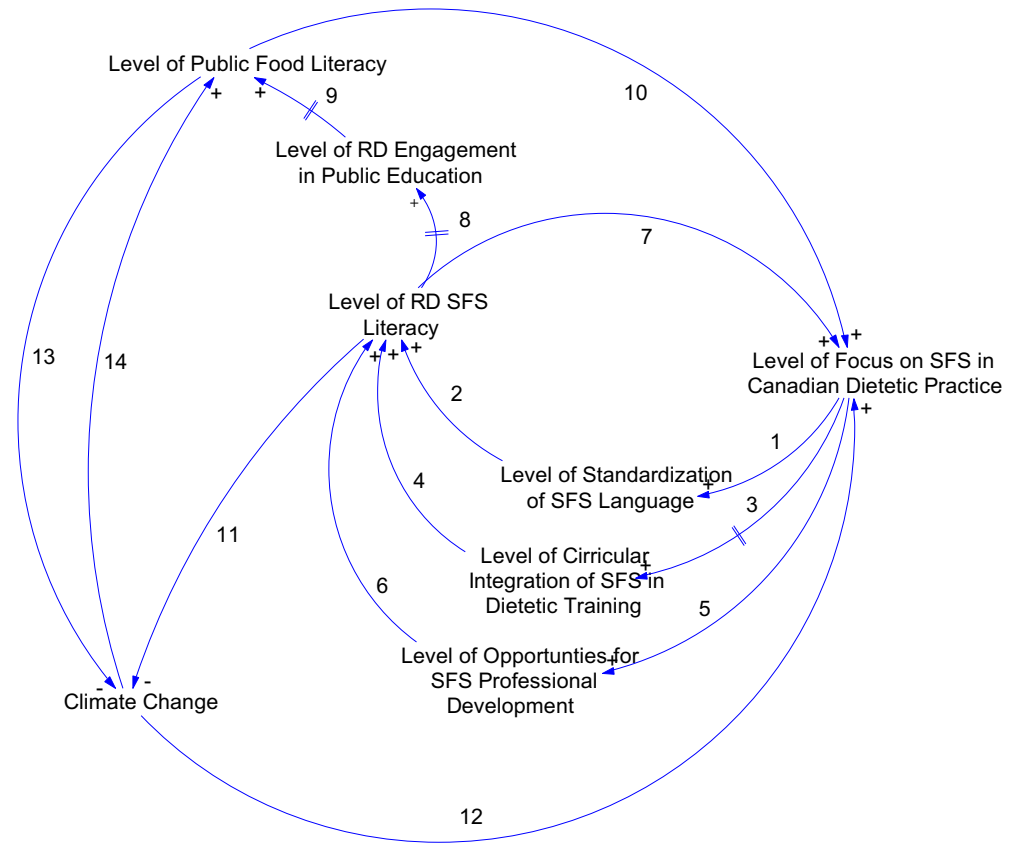

Fig. 2 System of interest: food literacy as part of sustainable food systems. Figure 2 prepared using Vensim ${ }^{\circledR}$ 7.3.5. 2019 
Table 5 for the details of how variables are related). Figure 2 also illustrates how increasing food literacy may have impacts across scales and other variables in the socioecological system, which, through feedback loops, influences the cultural paradigm within the profession positively. Over an extended period of time, the variables will not increase infinitely (i.e., continue to increase the level of focus of the profession on SFS indefinitely). The diagram is a simplification of realty in the near future.

\section{Discussion}

In line with the purpose of this paper, first the results are discussed with respect to how the procedure for community level assessment of contributions to SFS development addresses the two central challenges highlighted, and second, the results are discussed with respect to direct opportunities for RDs.

\section{Challenge 1: A Lack of Methods and Tools that Support Synergistic SFS Progress Among Communities and across Scales, While Involving Community in Developing Community Relevant Indicators}

Using the Delphi Inquiry method was helpful for inviting the community to define their own vision and goals for SFS, as well as barriers, actions and relevant indicators for assessment purposes. This engagement is important for continued learning through contextually relevant knowledge (Lyytimäki et al. 2018; Stoecker 2013; Yamala 2004), and Alrøe and colleagues emphasise the importance of learning opportunities that are created by SFS assessments (Alrøe et al. 2016). The Delphi Inquiry method used in this research (Carlsson et al. 2017b, 2019a) invited community members, as community experts with relevant knowledge to share, through iterative dialogue about SFS, between themselves, and with the research team. It exposed common, dissenting and diverging views in an anonymous way, such that they were open to discussion. The process was educational and contributed to the sharing of contextually relevant knowledge between participants and researchers.

Embedding learning is important as it enhances readiness to adapt to a continually changing set of conditions. As stated in the results, the vision of SFS and identified themes for measurement represent what was important to this community at the time the Delphi Inquiry process was conducted. As conditions of the system change, there will be continual need to reiterate the process - revisit the vision, actions and indicators and redefine as needed, and it is important that those be informed by a breadth of different types of knowledge - researchers, community members, professional communities, etc. (Brown et al. 2010). Ideally, as communities reiterate this process, they will become more comfortable and adept at the collaborative process and identifying opportunities for positive change.

While it is important to invite communities to determine their own priorities and relevant ways of measuring progress toward those priorities, it is also important that there is overall alignment among communities. In today's highly globalised food systems, and given the urgent calls for addressing important sustainability crises (Development Initiatives 2017; Food and Agriculture Organization of the United Nations 2015; United Nations Climate Change 2015), there is also a need for collaborative, concerted efforts across scales. Framing data collection and analysis using the FSSD, and in particular, using the SPs as concrete parametres defining sustainability supported overall alignment between communities and across scales. 
Table 5 Explanation of causal loop diagram links in Fig. 2

Link Action or Process Represented

number

1
This link is positive. An increased level of focus on SFS in Canadian dietetic practice likely increases the level of standardization of language (terms and concepts) in the community, and the related indicator is currently increasing.

This link is positive. An increased level of standardization of language around SFS likely increases the level of RD SFS literacy in the profession, thus mitigating susceptibility to misinformation. As there is no adequate indicator for the level of RD SFS literacy identified for this article (listed as helpful but inadequate on its own in Table 4), and since this is considered difficult, the level of standardization of language is proposed to be used as a proxy.

This link is positive. An increased level of focus on SFS in Canadian dietetic practice likely increases the level of curricular integration of SFS into dietetic training in formal educational structures such as university and practicum curriculum. However, the related indicator is currently static. This is likely due to a delay as indicated in the diagram. There is significant inertia and lead time in formal educational structures.

This link is positive. An increased level of curricular integration of SFS into dietetic training likely increases the level of RD SFS literacy in the profession. This is also proposed to be used as a proxy.

This link is positive. An increased level of focus on SFS in Canadian dietetic practice likely increases the level of opportunities for SFS professional development through specific courses and resources (webinars, conference sessions, and other learning resources from DC), and the related indicator is currently increasing. Failure to further develop these resources would mean integration of SFS into dietetic practice would be slower, as it would then be more dependent on curricular integration in formal educational structures and new graduates from these entering the workforce.

This link is positive. An increased level of opportunities for SFS professional development likely increases the level of RD SFS literacy in the profession. This is also proposed to be used as a proxy.

This link is positive. If the level of RD SFS literacy increases, it will likely reinforce the cultural paradigm supporting SFS as a focus area for dietetic practice. That is, it will 'institutionalise' SFS as a priority. This reinforcing dynamic will be valid for some time. When the variables reach high levels, other dynamics will come in, which are now not represented in the diagram. Over extended time the variables will not increase infinitely. The diagram is a simplification of realty in the near future.

This link is positive. An increased level of RD SFS literacy likely increases the level of engagement in public education activities, through several mechanisms in Table 3: Identify and dispel common myths about SFS; Develop a case for sustainability using publicly accessible language; Educate for SFS literacy in public schools \& community, and advocate for curricular integration; Educate about satisfying food and nutritional needs in a way that is less reliant on energy intensive imports (which, for the purposes of this article we have modified to a more broad focus on resource use for all foods, not unique to imports); and, Advocate and educate for prioritizing cultural foods. However, the indicator for level of RD engagement in public education is static at zero: there are currently no resources that support public engagement processes (i.e., applied tools), and therefore none to download. Reasons for this could include lack of time and money at the organizational level to develop such tools, and hence the time delay in the diagram.

Furthermore, the indicator is listed as helpful but inadequate on its own in Table 4. Action areas other than facilitating knowledge development have also been identified (Carlsson et al. 2019a), and the development of related indicators for those would support stronger assessment.

This link is positive. With increasing efforts to translate knowledge, influence behaviour, and influence structural policies that support SFS, the level of public food literacy will likely increase. However, as discussed in link 8, the indicator for level of RD engagement in public education is static at zero. While helpful but inadequate on its own, this indicator points to likely low-to-no change at the tail end of this link. The indicator for the level of public food literacy is currently unknown. However, the related process (level of RD engagement in public education) indicator can be used as a proxy for this unknown. In the present state, that indicates that public food literacy, as defined in this paper, is likely low, as is the case community's contributions to SFS. As such, this highlights a gap in both measurement and action, and thus highlights a 
Table 5 (continued)

Link Action or Process Represented

number

strategic focus area for dietetic practice. Furthermore, there is significant inertia and lead time; once resources become available and are being downloaded and used, it will take time to influence behaviour and the change will not happen in a uniform manner. This is indicated as a delay in the diagram.

10 This link is positive. If the level of public SFS literacy increases, this likely increases broader public awareness and in turn the perceived importance of SFS in Canadian dietetic practice. This link is not further elaborated in this article.

11 This link is negative. If the level of RD SFS literacy increases, the professionals will be able to apply their skills to influence food systems and diets in a way that likely reduces climate change. This is an example where the effects would be amplified through links 8,9 and 14 . In this diagram we use climate change as an example, as food systems and diets have climate change mitigation potential (IPCC 2018). One example identified in the Delphi Inquiry process was through lowering energy use (Carlsson et al. 2019a), which in Canada comes primarily from fuels that contribute to climate change. Indicators related to energy use in food systems and diets need to be identified. This link is not further elaborated in this article.

12 This link is positive. If climate change increases (worsens), this will likely influence both directly (link 11), and indirectly (links 12,9), the perceived importance of SFS in Canadian dietetic practice. This link is not further elaborated in this article. However, measures of climate change exist (Intergovernmental Panel on Climate Change 2014; IPCC 2018) and that outcome indicator is increasing. Also, exploratory surveys with DC members show that $78 \%$ felt that SFS is relevant to their day-to-day practice (Finlay and Carlsson 2019). This could be tracked as an indicator of perceived importance.

13 This link is positive. If climate change increases and impact the daily lives of more people, the perceived importance and relevance of food choices that mitigate climate impacts and related knowledge will likely increase, which is part of public SFS literacy. This link is not further elaborated in this article.

14 This link is negative. If the level of public SFS literacy increases, including knowledge about food habits that mitigate climate change, the level of climate change will likely decrease. While knowledge/literacy does not necessarily result in behaviour change, it is one important contributor. This link is not further elaborated in this article. However, sustainability consciousness is one factor influencing Canadians to consume less beef (Charlebois et al. 2016), which is one food product with high climate impacts (Chai et al. 2019; Gerber 2013; Willett et al. 2019).

The FSSD was used here to inform actions that can contribute positively toward sustainability by addressing a barrier articulated as a violation of one or more SPs, and to identify related process indicators used to monitor progress toward sustainability, regardless of scale. The FSSD also supported goals to involve community. It provided procedural support for cocreation of sustainable visions, assessment of the current reality, generation of possible actions to close the gap, and prioritization of such actions into strategic plans.

\section{Challenge 2: The Absence of Adequate Data Relevant to the Community}

The complex network of variables that comprise the food system often create interactions across geographic scales. This means that a change in one variable can either moderate or amplify the state of a second variable that is far away (Dyball and Newell 2015), e.g., the weather in Southern Asia impacting crop production in Europe. Overall, the system behaves in ways that are the product of these many interactions, but like many other complex public health challenges (Leischow and Milstein 2006), to examine the whole food system can be 
overwhelming or too time consuming (Dyball and Newell 2015), resulting in complexity paralysis. This paralysis is in part explained by the fact that our ability to understand will always be limited by our partial and subjective stance in the question (Brown et al. 2010; Flood 2010). Conversely, it is limiting to examine individual parts of the system in isolation, for example, measuring the level of food literacy without also examining the many factors that impact food literacy, and those impacted by the level of food literacy. In fact, it is likely to mask an unintended consequence that result from well-intended actions. The CAT facilitated focus on a specific variable within the subsystem of interest (RD SFS literacy), and affiliated variables (ecosystem, human wellbeing, cultural paradigm). Mapping these variables using CLDs helps illustrate indicator relationships and thus, informs dynamic hypotheses about interactions between variables (at a chosen level of granularity) that drive the overall system behavior (Cumming and Norberg 2008).

The CAT has limitations if causal relationships in the data are not known (see limitations), but the tool allows for other forms of knowledge to provide insight, i.e., practical/professional knowledge (Brown et al. 2010). If the expertise of the community (in this case RDs) agrees that there is a reasonable hypothesis to make, then one can proceed under that assumption. As such, the known data that interacts with a variable of interest can become a proxy measure by informing a dynamic hypothesis about its state - one that is subject to change where empirical data arises. In many cases, some data is available; often the available data relates to national or global level outcomes (e.g., climate change) and the use of the proposed methods can accommodate integration of data points that are, or become, available. In the case example, indicators for public food literacy are currently unknown. Related process indicators (level of $\mathrm{RD}$ engagement in public education) can be used as a proxy for this unknown. From a practical perspective, process indicators (i.e., those related to actions) are relatively available or easily gathered at a community level (see examples in Table 4). In the present state, it indicates that public food literacy, as defined in this paper, is likely low, as is the case community's contributions to SFS. As such, this also highlights a gap in both measurement and action, and thus highlights a strategic focus area for dietetic practice.

Though from an assessment perspective it is quantitatively imperfect, in the absence of data, the use of the CAT helped to map informed and dynamic hypotheses about how actions will drive movement in the subsystem of interest, including across scales. It can do so in absence of detailed empirical data of two kinds. The first is empirical data measuring the state of the variable for which there is currently no validated measure - e.g., food literacy in this research, though some work is being done to develop a tool (Boucher et al. 2017). The second is empirical data demonstrating the relationship between variables (e.g., SFS integration in dietetic education leads to increasing SFS literacy among RDs).

A further advantage of focusing on process related indicators is that they help to elucidate the "role" of the community in driving change, one that might otherwise not be so clear in such complex issues. It also highlights that the issues are not the purview of dietetics alone (e.g., energy use). In this paper, we identify potential actions RDs might pursue that could contribute to positive change in food literacy. Many other potential actions exist and are strategic to a different community (geographic, professional or other), and the assessment process described in this article leaves space for collaborative opportunities. Additional process links driven by actions in other sectors and disciplines are easily added to the assessment process.

See Appendix 1 for the detailed (step-by-step) procedure used for community level engagement in, and assessment of, contributions to SFS development. It is informed by evidence and experience gained while working with the challenges highlighted in this paper 
and previous, related work (Carlsson et al. 2017b, 2019a). In Appendix 1, the procedure in Step 2 (2.1-2.4) was not co-developed with the case community. It requires more research to test and improve on how it can support communities in assessing their contributions to SFS over time.

\section{Opportunities for Dietitians in Contributing to SFS Development}

In the example used in this article, we follow RD expertise that increasing RD SFS literacy will contribute to broader public food literacy, and potentially positive climate outcomes. Results show that in the present state, public food literacy is likely low, and that RD engagement with public education activities is also likely low. There is therefore a gap in action, and this highlights a strategic focus area for dietetic practice. Namely, there is a need for resources that support RDs to apply SFS in public education and outreach activities, such as those listed in Table 3:

- Identify and dispel common myths about SFS.

- Develop a case for sustainability using publicly accessible language.

- Educate for SFS literacy in public schools and community, and advocate for curricular integration.

- Educate about satisfying food and nutritional needs in a way that is less reliant on energy intensive imports, which, for the purposes of this article, we have modified to broader focus on resource use for all foods, not unique to imports.

- Advocate and educate for prioritizing culturally relevant foods.

There are also opportunities to embed SFS concepts into RD education and training (Carino et al. 2019; Pettinger 2018; Wegener 2018) that are likely to have positive feedback on RD SFS Literacy and therefore uptake of resources and support for public outreach activities.

Furthermore, there a gap in data for measurement purposes. There would be no change in data on this action area.

Because we have used an isolated example of knowledge development for measurement purposes, the importance of other actions in achieving these outcomes are not captured in this subsystem of interest, for example, advocacy for the prohibition of marketing unhealthy food to children, and systematic dismantling of income inequalities to address household food insecurity (Carlsson et al. 2019a). A full assessment of this, or any community's contributions to SFS, would require multiple iterations using the various identified themes and indicators, and is beyond the scope of this paper. It would also contribute to a better understanding of the relationships in links 8 and 9 for both measurement and action purposes.

As outlined in the methods section, the CAT was developed to theorise the factors that contribute to our cultural adaptive capacity - in this example, the ability of the dietetics profession to respond to changing environmental conditions such as climate change, which signal a need for a higher level of importance to be placed on SFS. While not all members of this case community may share a worldview with a high level of focus on SFS, according to cultural adaptation theory, the success of our ability to foster and maintain sustainable communities (defined here using the SPs of the FSSD), rests on the ability to collectively develop embedded ways of thinking and doing that facilitate adaptive (as opposed to maladaptive) progress. The feedback loops in Fig. 2 also highlight opportunity for intentionally shaping cultural adaptation. Decisions made at a community level have broader impacts in the 
socioecological system that, in turn, can create positive, or negative feedback to the state of cultural paradigms. This can up or downregulate the relative strength of the SFS focus within the community culture. For example, by embedding SFS concepts into RD education and training, this will increase the level of RD SFS literacy, which is likely to manifest in the many areas of dietetic interaction with the public, and theoretically strengthen community level infrastructure that, in turn, amplifies an SFS positive paradigm.

\section{Limitations}

In this research, the Delphi Inquiry process was facilitated using online survey software due to the geographically disparate community, and required that participants have internet access. This vehicle could affect the validity of future community work given a different context (e.g., without access to internet, literacy, etc.). The vehicle for the Delphi Inquiry process can be adapted to the community context (e.g., meetings, interviews, etc.) and research resources.

The theoretical nature of the relationships between variables is a limitation of the methods used. There is a subsequent opportunity to study the nature of the relationships between the variables (i.e., correlated, causal, directional, magnitude, etc.) in order to continue to adapt the model and assumptions. The methods are also limited by the use of a subsystem of interest to illustrate the example. A comprehensive analysis would require examining many subsystems simultaneously, and may come with unforeseen challenges. In the context of the identified challenge, where fine grained community level indicators are not consistently available, it should be noted that data collection is still required. However, it is generally easier for communities to collect action oriented, or process data, such as audits of what is being done, than outcomes data like the greenhouse gas emissions of a specific community-although if available, it can easily be included.

As mentioned in the results, the CLD used to guide assessment is a simplification of realty in the near future. As with any attempt to assess dynamic systems, it should be reviewed and updated periodically, along with the vision, barriers and appropriate actions.

\section{Conclusions}

The efforts of this paper to assess contributions to SFS are not about measurement for the sake of mastery over the system; they remain focussed on process-oriented assessment that is useful, in the context of partial and subjective understandings of a dynamic system, to continually adjust action.

The procedure described in this article has several advantages for community engagement in addressing some of the systemic challenges in food systems, and highlights both theoretical and practical insights, including some specific for the community of Canadian dietitians.

This paper is builds on previous theoretical frameworks by combining the FSSD and CAT in order to support community engagement with, and assessment of, contributions to SFS, while addressing the assessment challenges outlined: 1) a lack of methods that support alignment between communities and across scales, balanced against the need to involve the community in developing relevant indicators; and 2) the absence of adequate, fine grained data relevant to the community. The results demonstrate several additional advantages in this context: it allowed for multiple types of knowledge (e.g., professional, community) to be used in indicator development; by using process indicators, it helped illustrate the community's contributions to SFS development and thus has immediate action-oriented relevance to the 
community; and emphasized the importance of cultural paradigms in a community's capacity to adapt to changing environmental conditions is emphasised.

In this research, facilitating SFS literacy within the profession is a first step in addressing barriers identified by the community, while generating positive feedback loops that strengthen the SFS focus within the professional cultural paradigm that have further effects on human health and well-being, and ecological systems. In such a way, RDs can intentionally amplify adaptations for, and positive contributions to, SFS development. As system conditions change, RDs will be able to reassess where it is most strategic to focus their actions for increasing food systems sustainability, and the procedure outlined in this paper (for details, see Appendix 1) can be used again for that purpose. It may also be useful bring other communities that want to contribute to, and collaborate on SFS work, and researchers interested in community level SFS action and measurement.

Acknowledgment The authors would like to thank Anne Stieger, Jesper Dorph and Jacob Carver for their work on indicators, and to Robert Dyball and Federico Davila for their feedback on our application of the Cultural Adaptation Template.

Funding Open access funding provided by Blekinge Institute of Technology. The authors gratefully acknowledge financial support from VINNOVA (Swedish Governmental Agency for Innovation Systems), Acadia University Research Fund and Blekinge Institute of Technology, as well as the International Confederation of Dietetics Associations.

\section{Compliance with Ethical Standards}

Conflict of Interest The authors declare that they have no conflict of interest.

\section{Appendix 1}

$\begin{array}{lll}\text { Step Method/ Tools } \quad \text { Brief Description } & \begin{array}{l}\text { Advantages and Limitations } \\ \text { (Further details, justification and discussion) }\end{array}\end{array}$

1: Engage community in participatory, multidimensional approaches to conceptualizing their role in SFS

1.1 Delphi Inquiry; Invite diverse members of the community Online survey software can ensure

FSSD

Backcasting from SPs to participate in panel to discuss: (A) a vision of SFS, (B) the barriers and supports in today's reality for the community, (C) possible actions for moving toward the vision, and D), which actions are strategic to prioritise

Include a question about relevant indicators to measure progress toward the vision anonymous responses and encourage honesty

Technology access might be a barrier in some contexts and other formats for the dialogue are possible (e.g., meetings, interviews)

The panel make-up should strive to include diverse disciplines, sectors, or knowledge domains

Maximise engagement, realizing that traditionally marginalized groups might take targeted efforts to engage

Indicators may not be available or of high quality, but this procedure can inform the development of relevant indicators

Further reading: (Carlsson et al. 2017b, 2019a) 
Step Method/ Tools Brief Description Advantages and Limitations

(Further details, justification and discussion)

1.2 Delphi Inquiry; Questions asked iteratively in

Qualitative

analysis with After each round, analyse and organise

FSSD (5LM; data from each round using 5LM to

$\mathrm{SP})$ separate, e.g., possible actions from visionary concepts

Concurrently analyse and organise data using SPs to evaluate comprehensiveness of the responses with respect to sustainability

Delphi Inquiry

Use analysis to provide a composite summary between each round for consideration by panel prior to answering questions again

1.4 Delphi Inquiry In second and third rounds, explicitly ask for panel to amplify, disagree, or ask for clarification re: composite summary

1.5 Delphi Inquiry; FSSD

Backcasting from SPs
End Delphi Inquiry process with face-to-face workshop to finalise data, discuss outstanding issues

Finalise D-Step: facilitate conversations around which of the actions are "upstream" or high-leverage.
Iterative nature supports member checking, increases learning between all participants, including the research team (or any team facilitating the procedure, increases ownership and buy-in

Helps organise and structure input from diverse knowledge domains so that it is comparable. a priori theming will help important ideas emerge that may have been recorded under another question.

SP analysis: supports facilitating dialogue about comprehensive sustainability

(Optionally) introduce SPs to participants, depending on context, time and appropriateness to audience (time is required to learn and work with SPs) Best to use it as part of the analysis here, but optional as it can be done as part of 1.6 and 1.7.

Further reading: (Carlsson et al. 2017b, 2019a)

Supports member checking, increases learning between all participants, including the facilitating team

Time consuming to produce. Be aware of that and plan accordingly.

Further reading: (Carlsson et al. 2017b)

Helps build trustworthiness in results, learning across knowledge domains, and highlight potential areas of tension that require addressing

Further reading: (Carlsson et al. 2017b, 2019a)

Helps build clarity and relationships

Breaks anonymity

May result in participant voices being "silenced" somewhat by group dynamics or ability to attend

Further reading: (Carlsson et al. 2017b)

1.6-1.7 Can be done in advance of the concluding workshop, and there further refined, or completed after the workshop, depending on timing and purpose

1.6a Qualitative open Finalise list of multidimensional themes coding relevant to the community level that

List of themes used to frame (outcome) indicators capture the vision of success (A) within SPs.

Concrete definition of sustainability defines what is and is not sustainable within vision themes, and provides parametres to align visions and action across different communities and scales Further reading: (Carlsson et al. 2017b)

1.6b Local-to-global Populate community layer of framework Optional assessment for local-to-global SFS indicators framework 
Step Method/ Tools Brief Description Advantages and Limitations

(Further details, justification and discussion)

Helps conceptualise relevant themes as related to themes established by global expert panel.

Can add layer of complexity, may not be necessary

Further reading: (Carlsson et al. 2017b)

1.7 Qualitative analysis with FSSD (SPs)

Organise such that themes are related to key barriers to that theme, barriers are aligned articulated as SPs violations, and high-leverage actions are aligned with barriers.

Delphi Inquiry

After the workshop, provide final summary report. If possible, include steps $1.6-1.8$
Concrete definition of sustainability (parametres) that define what is and is not sustainable

Barriers articulated as SPs violations helps isolate how communities can, through barrier-specific actions, drive progress in a theme toward a more sustainable state, even across different communities and scales

Further reading: (Carlsson et al. 2019a)

Final summary report can be used as a strategic roadmap, or a foundation for similar strategic work (Carlsson et al. 2017a, 2019b)

Further reading: ((Carlsson et al. 2017b, 2019a)

1.1-8 Outcomes As a result of Phase 1, the community will have defined:

1. A vision statement and list of themes which capture the important concepts in the vision.

2. Barriers to the vision, articulated as drivers of unsustainable conditions.

3. High leverage actions that address the barriers, and a list of potential and relevant indicators for both actions and the vision.

\section{Apply systems thinking and tools to guide assessment and evaluation}

2.1 CAT;

Causal Loop

Diagrams
Use CAT to delimit a system of interest (can be one focus theme and several related themes)

Refer to community identified barriers, actions related to that theme (step 1.7).

Use CLDs to visualise the system of interest, guided by CAT
Helps to avoid complexity paralysis, highlight how finer grained (community level) subsystems are linked to broader goals

Can involve the community in this phase (in face-to-face workshop), but it can also be developed parallel, or afterwards, depending on appropriateness and resource capacity

CLDs informed by the CAT not exclusive of the role of other sectors and disciplines to contribute positive change

Multiple systems of interest possible

Using community identified barriers and indicators allows other forms of knowledge (other than academic) to be used to develop indicators

Process indicators help elucidate the 'role' of the community in driving change 


$\begin{array}{lll}\text { Step } \quad \text { Method/ Tools } \quad \text { Brief Description } & \begin{array}{l}\text { Advantages and Limitations } \\ \text { (Further details, justification and discussion) }\end{array}\end{array}$
Local-to-global Screen indicators for: high-quality, Community identified may not meet assessment practical, sufficient, necessary screening criteria

Identify and collect suitable alternatives if Strive to develop or adjust indicators that needed meet criteria, while being true to the intention of community indicators

$2.4 \quad$ Delphi Inquiry;

Outcomes and process indicators become variables in the CAT-informed CLD.

Data may still be missing

Evaluate increasing/decreasing state of outcome or process to understand whether actions drive toward or away from sustainable state, and where potential points of leverage (community level actions) may lie.

Process indicators help inform dynamic hypotheses about indicator interrelationships, including across scales, in the absence of data.

CAT theory helps develop inferences about the influence of sociocultural norms, and opportunities to shape SFS-sensitive cultural paradigms

Requires familiarity with using and reading CLDs

CLDs of various subsystems can be combined to examine the overall behavior of a larger system with respect to sustainability.

\section{1-4 Outcomes}

As a result of Phase 2, the team and community will have defined:

1. A subsystem of interest (or multiple).

2. A revised list of relevant indicators that measure

both actions (process indicators) and vision themes (outcomes indicators).

3. A "map/diagram" that conceptualises how actions at the community level contribute to the vision and broader global SFS development, such that assessments can be made.

Food systems are a part of dynamic socioecological systems. As such, this procedure is meant to be used iteratively, as time and resources allow. Iterative use will allow for continued follow-up between all stakeholders, as-needed revision of the strategic plan that it informs, and even perhaps the original vision

Open Access This article is licensed under a Creative Commons Attribution 4.0 International License, which permits use, sharing, adaptation, distribution and reproduction in any medium or format, as long as you give appropriate credit to the original author(s) and the source, provide a link to the Creative Commons licence, and indicate if changes were made. The images or other third party material in this article are included in the article's Creative Commons licence, unless indicated otherwise in a credit line to the material. If material is not included in the article's Creative Commons licence and your intended use is not permitted by statutory regulation or exceeds the permitted use, you will need to obtain permission directly from the copyright holder. To view a copy of this licence, visit http://creativecommons.org/licenses/by/4.0/.

\section{References}

Abson DJ, Fischer J, Leventon J, Newig J, Schomerus T, Vilsmaier U, von Wehrden H, Abernethy P, Ives CD, Jager NW, Lang DJ (2017) Leverage points for sustainability transformation. Ambio 46(1):30-39. https://doi.org/10.1007/s13280-016-0800-y

Aleksandrowicz L, Green R, Joy EJM, Smith P, Haines A (2016) The impacts of dietary change on greenhouse gas emissions, land use, water use, and health: a systematic review. PLoS One 11(11):e0165797. https://doi. org/10.1371/journal.pone.0165797 
Allen T, Prosperi P (2016) Modeling sustainable food systems. Environ Manag 57(5):956-975. https://doi. org/10.1007/s00267-016-0664-8

Allen T, Prosperi P, Cogill B, Padilla M, Peri I (2019) A Delphi approach to develop sustainable food system metrics. Soc Indic Res 141(3):1307-1339. https://doi.org/10.1007/s11205-018-1865-8

Alrøe HF, Moller H, Læssøe J, Noe E (2016) Opportunities and challenges for multicriteria assessment of food system sustainability. Ecol Soc 21(1):503-510. https://doi.org/10.5751/ES-08394-210138

Berry E, Dernini S, Burlingame B, Meybeck A, Conforti P (2014) Food security and sustainability: can one exist without the other? Public Health Nutr 18:2293-2302

Boucher BA, Manafò E, Boddy MR, Roblin L, Truscott R (2017) The Ontario food and nutrition strategy: identifying indicators of food access and food literacy for early monitoring of the food environment. Health Promot Chronic Dis Prev Can 37(9):313-319. https://doi.org/10.24095/hpcdp.37.9.06

Broman GI, Robèrt K-H (2017) A framework for strategic sustainable development. J Clean Prod 140(Part 1): 17-31. https://doi.org/10.1016/j.jclepro.2015.10.121

Brown VA, Harris JA, Russell JY (2010) Tackling wicked problems through the transdisciplinary imagination. Earthscan

Carino S, McCartan J, Barbour L (2019) The emerging landscape for sustainable food system education: mapping current higher education opportunities for Australia's future food and nutrition workforce. J Hunger Environ Nutr:1-22. https://doi.org/10.1080/19320248.2019.1583621

Carlsson L, Callaghan E, Dorph JR (2017a) Sustainable food systems that promote healthy diets: A proposed roadmap for dietitians of Canada. (p. 17). Blekinge Institute of Technology. https://www.bth.se/eng/foodcommons/

Carlsson L, Callaghan E, Morley A, Broman G (2017b) Food system sustainability across scales: a proposed local-to-global approach to community planning and assessment. Sustainability 9(6):1061-1075. https://oi. org/10.3390/su9061061

Carlsson L, Callaghan E, Broman G (2019a) How can dietitians leverage change for sustainable food systems in Canada? Can J Diet Pract Res 25(1):1-8. https://doi.org/10.3148/cjdpr-2019-005

Carlsson L, Callaghan E, Laycock-Pederson B (2019b) Building common ground for sustainable food Systems in Nutrition and Dietetics. Acadia University; Blekinge Institute of Technology, pp 1-28

Chai BC, van der Voort JR, Grofelnik K, Eliasdottir HG, Klöss I, Perez-Cueto FJA (2019) Which diet has the least environmental impact on our planet? A systematic review of vegan, vegetarian and omnivorous diets. Sustainability 11(15):4110. https://doi.org/10.3390/su11154110

Charlebois S, McCormick M, Juhasz M (2016) Meat consumption and higher prices. British Food Journal; Bradford 118(9):2251-2270. https://doi.org/10.1108/BFJ-03-2016-0121

Checkland P (1981) Systems thinking, systems practice (Vol. 14). Wiley, Chichester

Colombo PE, Patterson E, Elinder LS, Lindroos AK, Sonesson U, Darmon N, Parlesak A (2019) Optimizing school food supply: integrating environmental, health, economic, and cultural dimensions of diet sustainability with linear programming. Int J Environ Res Public Health 16(17):3019. https://doi.org/10.3390 /ijerph16173019

Cullen T, Hatch J, Martin W, Higgins JW, Sheppard R (2015) Food literacy: definition and framework for action. Can J Diet Pract Res 76(3):140-145. https://doi.org/10.3148/cjdpr-2015-010

Cumming GS, Norberg J (2008) Scale and complex system. In: Complexity Theory for a Sustainable Future. Columbia University Press, pp 246-276

Davila F, Dyball R, Amparo JM (2018) Transdisciplinary research for food and nutrition security: examining research-policy understandings in Southeast Asia. Environ Dev 28:67-82. https://doi.org/10.1016/j. envdev.2018.10.001

Development Initiatives (2017) Global nutrition report, 2017: nourishing the SDGs. Development Initiatives. http://globalnutritionreport.org/

Dietitians of Canada-Sustainable Food System (n.d.) Retrieved July 10, 2020, from https://www.dietitians. ca/Advocacy/Priority-Issues-(1)/Food-Policy/Sustainable-Food-System

Dyball R, Newell B (2015) Understanding human ecology: a systems approach to sustainability. Routledge

EAT (n.d.) EAT Lancet Commission Summary (Healthy Diets From Sustainable Food Systems). Retrieved January 17, 2019, from https://eatforum.org/content/uploads/2019/01/EAT-Lancet_Commission_ Summary_Report.pdf

El Hassan M (2019) Goats, People and Rangelands: Analysis of the Rangeland Goat Industry as a Complex Social Ecological System [ProQuest Dissertations Publishing]. https://search.proquest. com/docview/2353152761/abstract/C5A2D0DE39414297PQ/1

Feenstra G, Jaramillo C, McGrath S, Grunnell AN (2005) Proposed indicators for sustainable food systems (p. 121). Ecotrust

Finlay E, Carlsson L (2019) Survey of dietitians of Canada members on sustainable food systems perceptions, practice and needs [data brief]. Acadia University. https://www.bth.se/eng/food-commons/ 
Flood RL (2010) The relationship of "systems thinking" to action research. Systemic Practice and Action Research; New York, 23(4), 269-284. http://dx.doi.org.ezproxy.acadiau.ca:2048/10.1007/s11213-0109169-1

Food and Agriculture Organization of the United Nations (Ed) (2015). The state of food insecurity in the world. Meeting the 2015 international hunger targets: taking stock of uneven progress. FAO. http://www.fao.org/3 /a-i4646e.pdf

Fraser EDG, Dougill AJ, Mabee WE, Reed M, McAlpine P (2006) Bottom up and top down: analysis of participatory processes for sustainability indicator identification as a pathway to community empowerment and sustainable environmental management. J Environ Manag 78(2):114-127. https://doi.org/10.1016/j. jenvman.2005.04.009

Gamboa G, Kovacic Z, Di Masso M, Mingorría S, Gomiero T, Rivera-Ferré M, Giampietro M (2016) The complexity of food systems: defining relevant attributes and indicators for the evaluation of food supply chains in Spain. Sustainability 8(6):515. https://doi.org/10.3390/su8060515

Garnett T (2013) Food sustainability: problems, perspectives and solutions. Proc Nutr Soc 72(1):29-39. https://doi.org/10.1017/S0029665112002947

Garnett T (2014) Three perspectives on sustainable food security: efficiency, demand restraint, food system transformation. What role for life cycle assessment? J Clean Prod 73:10-18. https://doi.org/10.1016/j. jclepro.2013.07.045

Garnett T, Appleby MC, Balmford A, Bateman IJ, Benton TG, Bloomer P, Burlingame B, Dawkins M, Dolan L, Fraser D, Herrero M, Hoffmann I, Smith P, Thornton PK, Toulmin C, Vermeulen SJ, Godfray HCJ (2013) Sustainable intensification in agriculture: premises and policies. Science 341(6141):33-34. https://oi. org/10.1126/science. 1234485

Gerber PJ (2013) Tackling climate change through livestock: A global assessment of emissions and mitigation opportunities. Food and Agriculture Organization of the United Nations

Hasson F, Keeney S (2011) Enhancing rigour in the Delphi technique research. Technol Forecast Soc Chang 78(9):1695-1704. https://doi.org/10.1016/j.techfore.2011.04.005

Hebinck A (2018) Shaping sustainable food systems: Local participation in addressing global challenges [University of Stockholm]. http://www.diva-portal.org/smash/record.jsf?pid=diva2\%3A1252750 \&dswid=8103

Holmstedt L, Brandt N, Robèrt K-H (2017) Can Stockholm Royal Seaport be part of the puzzle towards global sustainability? - from local to global sustainability using the same set of criteria. J Clean Prod 140:72-80. https://doi.org/10.1016/j.jclepro.2016.07.019

Intergovernmental Panel on Climate Change (2014) Climate Change 2014 (Climate Change). UN Environment Programme (UNEP), World meteorological Organization (WMO). http://www.ipcc.ch/index.htm

IPCC (2018) Global warming of $1.5^{\circ} \mathrm{C}$.an IPCC special report on the impacts of global warming of $1.5^{\circ} \mathrm{C}$ above pre-industrial levels and related global greenhouse gas emission pathways, in the context of strengthening the global response to the threat of climate change, sustainable development, and efforts to eradicate poverty. United Nations environment program. https://www.ipcc.ch/2019/

IPES-Food (2015) The New Science of Sustainable Food Systems: Overcoming barriers to food systems reform. iPES Food. http://www.ipes-food.org/reports

Kezar A, Maxey D (2016) The Delphi technique: an untapped approach of participatory research. Int J Soc Res Methodol 19(2):143-160. https://doi.org/10.1080/13645579.2014.936737

Kok K, van Vliet M, Bärlund I, Dubel A, Sendzimir J (2011) Combining participative backcasting and exploratory scenario development: experiences from the SCENES project. Technol Forecast Soc Chang 78(5):835-851. https://doi.org/10.1016/j.techfore.2011.01.004

Landert J, Schader C, Moschitz H, Stolze M (2017) A holistic sustainability assessment method for urban food system governance. Sustainability 9(4):490. https://doi.org/10.3390/su9040490

Lang T, Mason P (2017) Sustainable diet policy development implications of multicriteria and other approaches. Proceedings of the Nutrition Society:1-6. https://doi.org/10.1017/S0029665117004074

Leischow SJ, Milstein B (2006) Systems thinking and modeling for public health practice. Am J Public Health 96(3):403-405. https://doi.org/10.2105/AJPH.2005.082842

Luke DA, Stamatakis KA (2012) Systems science methods in public health: dynamics, networks, and agents. Annu Rev Public Health 33(1):357-376. https://doi.org/10.1146/annurev-publhealth-031210-101222

Lyytimäki J, Antikainen R, Hokkanen J, Koskela S, Kurppa S, Känkänen R, Seppälä J (2018) Developing key indicators of Green growth. Sustain Dev 26(1):51-64. https://doi.org/10.1002/sd.1690

Meadows D (1999) Leverage points: places to intervene in a system. The Sustainability Institute

Morgan E, Tallontire A, Foxon TJ (2017) Large UK retailers' initiatives to reduce consumers' emissions: A systematic assessment. J Clean Prod 140:227-238. https://doi.org/10.1016/j.jclepro.2015.08.069

Nelson ME, Hamm MW, Abrams SA, Griffin TS (2016) Alignment of healthy dietary patterns and environmental sustainability: a systematic review. Adv Nutr 7:1005-1025. https://doi.org/10.3945/an.116.012567 
Neuman WL (2011) Social research methods: qualitative and quantitative approaches, 7th edn. Allyn \& Bacon

Peano C, Tecco N, Dansero E, Girgenti V, Sottile F (2015) Evaluating the sustainability in complex Agri-food systems: the SAEMETH framework. Sustainability 7(6):6721-6741. https://doi.org/10.3390/su7066721

Pettinger C (2018) Sustainable eating: opportunities for nutrition professionals. Nutr Bull 43(3):226-237. https://doi.org/10.1111/nbu.12335

Prosperi P, Allen T, Padilla M, Peri I, Cogill B (2014) Sustainability and Food \& Nutrition Security: a vulnerability assessment framework for the Mediterranean region. SAGE Open 4(2):2158244014539169. https://doi.org/10.1177/2158244014539169

Ranganathan J, Vennard D, Waite R, Dumas P, Lipinski B, Searchinger T (2011) Shifting diets for a sustainable food future. World Resources Institute, p 90

Rikkonen P, Aakkula J, Kaivo-oja J (2006) How can future long-term changes in Finnish agriculture and agricultural policy be faced? Defining strategic agendas on the basis of a Delphi study. Eur Plan Stud 14(2): 147-168. https://doi.org/10.1080/09654310500417962

Scialabba N, Food and Agriculture Organization of the United Nations, \& Food and Agriculture Organization of the United Nations. Natural Resources Management and Environment Department. (2014). SAFA guidelines: sustainability assessment of food and agriculture systems. (version 3.0.). Food and Agriculture Organization of the United Nations http://www.fao.org/nr/sustainability/sustainability-assessments-safa/en/

Sharp M (2016a) CEO ENDS interpretation [2016-2020] (Vision 2020). Dietitians of Canada

Sharp M (2016b) CEO Progress on organization priorities 2016-2020 (vision 2020). Dietitians of Canada. http://www.dietitians.ca/Member/Board-of-Directors/Priorities-and-Progress.aspx

Sobal J, Bisogni C (2009) Constructing food choice decisions. Ann Behav Med 38(Supplement 1):37-46. https://doi.org/10.1007/s12160-009-9124-5

Soubry B, Sherren K, Thornton TF (2020) Farming along desire lines: collective action and food systems adaptation to climate change. People Nature 2(2):420-436. https://doi.org/10.1002/pan3.10075

Sterling EJ, Filardi C, Toomey A, Sigouin A, Betley E, Gazit N, Newell J, Albert S, Alvira D, Bergamini N, Blair M, Boseto D, Burrows K, Bynum N, Caillon S, Caselle JE, Claudet J, Cullman G, Dacks R et al (2017) Biocultural approaches to well-being and sustainability indicators across scales. Nat Ecol Evol 1(12):17981806. https://doi.org/10.1038/s41559-017-0349-6

Stoecker R (2013) Research methods for community change: a project-based approach, 2nd edn. Sage Publications

The Economist Intelligence Unit, \& Barilla Centre for Food and Nutrition (2016) Food Sustainability Index. http://foodsustainability.eiu.com/

Thomas H, Perry EA, Slack J, Samra HR, Manowiec E, Petermann L, Manafò E, Kirkpatrick SI (2019) Complexities in conceptualizing and measuring food literacy. J Acad Nutr Diet 119(4):563-573. https://doi.org/10.1016/j.jand.2018.10.015

United Nations Climate Change (2015) The Paris Agreement. https://unfccc.int/process-and-meetings/the-parisagreement/d2hhdC1pcy

Wegener J (2018) Equipping future generations of registered dietitian nutritionists and public health nutritionists: a commentary on education and training needs to promote sustainable food systems and practices in the 21 st century. J Acad Nutr Diet 118(3):393-398. https://doi.org/10.1016/j.jand.2017.10.024

Willett W, Rockström J, Loken B, Springmann M, Lang T, Vermeulen S, Garnett T, Tilman D, DeClerck F, Wood A, Jonell M, Clark M, Gordon LJ, Fanzo J, Hawkes C, Zurayk R, Rivera JA, De Vries W, Majele Sibanda L et al (2019) Food in the Anthropocene: the EAT-lancet commission on healthy diets from sustainable food systems. Lancet 393:447-492. https://doi.org/10.1016/S0140-6736(18)31788-4

Yamala S (2004) Community-based participatory research for health. Journal of the Community Development Society 34(2):135-137

Yin RK (1994) Case study research: design and methods (vol 2nd). Sage Publications

Zurek M, Ingram J, Zimmermann A, Garrone M, Rutten M, Tetens I, Leip A, van'T Veer P, Verain M, Bauwman E, Marette S, Chang C, Latka C, Hornborg S, Ziegler F, Vervoort J, Achterbosch T, Terluin I, Havlík P, Depperman A (2016) Deliverable 1.1: A Framework for Assessing and Devising Policy for Sustainable Food and Nutrition Security in EU: The SUSFANS conceptual framework | SUSFANS (D 1.1; SUSFANS). https://susfans.eu/portfolio/framework-assessing-and-devising-policy-sustainable-food-andnutrition-security-eu-susfans

Publisher's Note Springer Nature remains neutral with regard to jurisdictional claims in published maps and institutional affiliations. 


\section{Affiliations}

\section{Liesel Carlsson $^{1,2} \cdot$ Edith Callaghan ${ }^{1,3} \cdot$ Göran Broman $^{1}$}

Liesel Carlsson

liesel.carlsson@acadiau.ca

1 Department of Strategic Sustainable Development, Blekinge Institute of Technology, Karlskrona, Sweden

2 School of Nutrition and Dietetics, Acadia University, Wolfville, Nova Scotia, Canada

3 Fred. C. Manning School of Business, Acadia University, Wolfville, Nova Scotia, Canada 